\title{
A Unique Approach to Treat Rheumatic Heart Disease by Using In Silico Modeling With Polymeric Nanoparticles
}

\author{
Ranajit Nath ${ }^{1}$, Ratna Roy ${ }^{2}$, Ritam Bandopadhyay ${ }^{3}$, Soubhik Bhattacharyya ${ }^{4}$, Riya Biswas ${ }^{5}$ \\ ${ }^{1}$ Department of Pharmaceutics, NSHM Knowledge Campus, Kolkata- Group of Institutions, Kolkata, West Bengal, \\ India \\ ${ }^{2}$ Department of Pharmacology, NSHM Knowledge Campus, Kolkata- Group of Institutions, Kolkata, West Bengal, \\ India \\ ${ }^{3}$ School of Pharmaceutical Sciences, Lovely Professional University, Phagwara, Punjab, India \\ ${ }^{4}$ Department of Pharmaceutics, NSHM Knowledge Campus, Kolkata- Group of institutions. \\ Kolkata, West Bengal, India \\ 5Jadavpur University, Department of Pharmaceutical Technology, Kolkata, West Bengal, India
}

\begin{abstract}
Article Info

Volume 8, Issue 3

Page Number : 885-893

Publication Issue

May-June-2021

Article History

Accepted : 18 June 2021

Published : 25 June 2021

Rheumatic heart disease (RHD) and its antecedent rheumatic fever (RF) is a serious health issue which targets mainly the elderly residing in developing countries. The main causative organism of RHD id group-A, $\beta$ - hemolytic streptococci (GAS). It is basically an autoimmune disease triggered by GAS infection which damage the heart valve tissue, resulting in chest discomfort and pain. Both Diltiazem, a benzothiazepine class of voltage gated L-type Ca2+ channel blocker and Norfloxacin, a fluroquinolone class of drug, are active against hemolytic streptococci (GAS) class of pathogen. These drugs show no kind of drug interaction when used together. So, combination of both these to drugs can be used in the treatment of RHD. A polymeric nanoparticle formulation is very useful in formulating a combination of drugs, as, nano formulation increases the bioavailability of the drugs in systemic circulation, and they did not hinder each other's absorption in the GIT. In this article we have developed and evaluated the polymeric nanoparticle formulation of norfloxacin and diltiazem combination, using chitosan as a polymer.

Keywords: Rheumatic heart disease, $\beta$ - hemolytic streptococci (GAS), docking, ADME, polymeric nanoparticles.
\end{abstract}

\section{INTRODUCTION}

Rheumatic heart disease (RHD) and its antecedent rheumatic fever $(\mathrm{RF})$ is a serious health issue which targets mainly the elderly residing in developing countries. The main causative organism of RHD id group-A, $\beta$ - hemolytic streptococci (GAS) ${ }^{[1]}$. It is basically an autoimmune disease triggered by GAS infection which damage the heart valve tissue, resulting in chest discomfort and pain ${ }^{[1]}$. There are

Copyright: @ the author(s), publisher and licensee Technoscience Academy. This is an open-access article distributed under the terms of the Creative Commons Attribution Non-Commercial License, which permits unrestricted non-commercial use, distribution, and reproduction in any medium, provided the original work is properly cited 
mainly two theories which describes the mechanism of GAS infection in humans. The first one is molecular mimicry theory and the second one is neoantigen theory. According to the molecular mimicry theory- host tissues and molecules on the causative organism are antigenically similar. Thus, when host defense mechanism targets the molecules on the causative organism, both host tissues and the causative organisms are damaged, leading to an autoimmune response. Two main antigens associated with GAS are surface $\mathrm{M}$ proteins and a group-A immunodominant antigenic determinant, GlcNAc ${ }^{[2]}$. Second theory is the "neo-antigen" theory. This is a more recent theory than the molecular mimicry theory. According to this theory- the $\mathrm{M}$ protein of GAS organism binds to the $\mathrm{CB}_{3}$ region of type-IV collagen and creates an autoimmune response against collagen ${ }^{[3]}$.

Nanoparticles which are nanosized colloidal structures composed of synthetic or natural polymers. The drug which is dissolved, encapsulated, and entrapped or it can be attached with a nanoparticle matrix. More than $50 \%$ of cardiovascular disease can be treated with this type of nano particles ${ }^{[4]}$.

All the nanoparticles are not used for medical purposes or treating purpose and now accepted definition of a nanoparticle size is 1 to100 $\mathrm{nm}^{[5]}$. Nanoparticles have a large (functional) surface area which helps to adsorb and bind and carry some compounds like drugs, and also some proteins and probes $^{[6]}$. Coatings of nanoparticles mainly used to prevent agglomeration and it also keeping the particles in colloidal suspension by using different polymer. Various synthetic polymers like polyethylene glycol (PEG), poly vinyl pyrrolidone (PVP) etc and natural polymers like dextran, agarose, gelatin, albumin, lectin, alginate, chitosan, pullulan etc and surfactants like sodium oleate, dodecylamine etc are used in nanoparticles ${ }^{[7]}$. The composition of the nanoparticle can be chosen depending to their specific and desired effect, and targeted environment. As an example, in liposome-based nanoparticles they are biologically and quickly degraded after delivery so specific composition is needed there because of the small size of nanoparticles which helps in allow the drug to bind and stabilization of particular proteins, and helps in penetration in cell membranes.

Advantages of nanoparticle is- It can cross the bloodbrain barrier (BBB) for brain diseases and disorders, it enhance the targeted intracellular drug delivery which ensure that the treatments are reaching in the correct structures and correct form inside the cell, combining the treatment and diagnosis, nanoparticles help in reducing the drug toxicity.

Diltiazem is a benzothiazepine class of voltage gated L-type $\mathrm{Ca}^{2+}$ channel blocker. It binds to the central cavity of the L-type $\mathrm{Ca}^{2+}$ channel, which consists of four homologous six transmembrane domain ion channel[ ${ }^{[8]}$. Thus, diltiazem decreases the $\mathrm{Ca}^{2+i o n}$ influx inside the cardiac cells and causes vasodilation. It is used in chest pain, arrythmia, angina pectoris and hypertension, to reduce chest discomfort ${ }^{[8]}$.

Norfloxacin is a fluroquinolone class of drug with a piperazine ring at $7^{\text {th }}$ carbon atom and fluorine molecule at $6^{\text {th }}$ carbon atom of the central structural carbon skeleton. They basically work by inhibiting bacterial DNA gyrase and Topoisomerase IV. Thus, destroying bacterial cells by stopping the bacterial DNA replication. Both of these enzymes are only present in bacterial cells and absent in normal human cells. So, they did not have any effect on mammalian DNA replication process. It was proven previously that Norfloxacin had great effectiveness in killing the streptococci class of microbes which is the main reason of $\mathrm{RHD}^{[9]}$.

So, in this study we are evaluating the activity of the combination of norfloxacin and diltiazem in RHD. We are using this combination because norfloxacin eradicates $\beta$ - hemolytic streptococci (GAS) form human body and diltiazem is helpful in reducing the chest discomfort, pain in RHD. Thus, cause and effect 
of the disease is treated simultaneously by using the combination.

Repurposing of realized little particles is by all accounts an unique productive path to create strong medications to conflict RHD in this brief timeframe period. Although, various endeavors were made to plan RHD inhibitors or utilize drug repurposing ways to deal with recognize hostile to RHD medications, which can go about as promising inhibitors against group A Streptococcus (GAS or Streptococcus pyogenes) targeted protein which is responsible for RHD.

\section{PDB ID 6BBW:}

Protein 6BBW in the protein data bank is- major pilin protein (T3.2) from Streptococcus pyogenes serotype GAS13637. streptococci (GAS) are the main causative organism in RHD. Molecular weight of this protein is $63 \mathrm{kDa}$. 6BBW protein forms the main backbone of the pilus structure, present in the GAS. Pili are extra cellular tubular like structures which helps in the motility of GAS organisms ${ }^{[10]}$.

\section{METHODS AND MATERIAL}

\section{Methods-}

\section{Particle size analysis:}

Particle size and particle size distribution had been evaluated via photo correlation spectroscopy equipped with Malvern PCS software.

According to MIE theory, in this formulation, the incident plane wave, and the scattering field are expanded into radiating spherical vector spherical harmonics. The internal field has expanded into regular vector spherical harmonics. The expansion coefficients of the scattered field can be computed by enforcing the boundary condition on the spherical surface. For particles that are both much larger and much smaller than the wavelength of the scattered light, there are simple and accurate approximations that suffice to describe the behavior of the system.
But for objects those sizes are within a few orders of magnitude of the wavelength ${ }^{[11]}$.

\section{Loading Efficiency:}

The drug content was determined by dissolving the nanoparticle in $0.1 \mathrm{M}$ hydrochloric acid. In this method 50mg of nanoparticles was weighed and transferred in $0.1 \mathrm{M}$ hydrochloric acid and continuously stirred until the whole content is dissolved in the acid and then it was filtered through a Millipore filter. After that the filtrate was analyzed in at a certain $\mathrm{nm}$ using UV/visible spectrometer. Finally, the loading efficiency is calculated by this formula: -

$$
\mathrm{L}(\%)=(\mathrm{Qn} / \mathrm{Wn}) \times 100
$$

where $\mathrm{Wn}$ is the weight of nanoparticles and Qn is the amount of drug present in nanoparticles ${ }^{[12]}$.

\section{Entrapment efficiency:}

For the determination the drug entrapment efficiency at first the amount of drug present in the clear supernatant $(\mathrm{w})$ after centrifugation was analyzed by $\mathrm{UV} /$ visible spectrometer at certain $\mathrm{nm}$. Then after determination the amount of drug in supernatant, this drug amount is subtracted from the amount of drug used during the preparation of nanoparticles (W). This (W-w) is the actual amount of drug present in the nanoparticles ${ }^{[13]}$.

The percentage entrapment is calculated by this equation

$\%$ Drug Entrapment $=[(\mathrm{W}-\mathrm{w}) / \mathrm{W}] \times 100$

\section{Drug-excipient compatibility study:}

Drug-excipient compatibility study is mainly for checking the effect of the interaction between drug and excipients in the dosage form. There are different type of method use in drug-excipient compatibility study:

1) In thermal methods: Differential Scanning Calorimetry (DSC) and Differential Thermal Analysis (DTA) 
2) In spectroscopy methods: FT-IR Spectroscopy, Fluorescence Spectroscopy/ Fluorometry, and Diffuse Reflectance Spectroscopy (DRS)

3) In chromatography methods: Thin Layer Chromatography (TLC), and Self Interactive Chromatography (SIC)

By the different type of method, we can observe the physico-chemical interaction and the drug-polymers interaction and also analyse drug, polymer and formulation separately ${ }^{[14]}$.

\section{Procedure:}

\section{1. ligand Screening}

For the initial Ligand screening purposes, a web-based tool named SwissADME (https://www.swiss adme.ch/) was used to eliminate a few compounds according to Lipinski's rule of five parameters ${ }^{[15]}$. For a compound to qualify as ligand it should Have $<500$ Da molecular weight, a high lipophilicity i.e. value of Log $\mathrm{P}$ being less than 5, hydrogen bond acceptors being less than 10 and $\mathrm{H}$-bond donors less than 5 . Any compound with more than 2 violations was ruled out for further study (Lipinski2004).

\section{Protein Preparation and Active site Determination.}

Required protein in pdb format was downloaded from the website rcsb.org, commonly known as the Protein Data Bank ${ }^{[16,17]}$. 3D conformers of the ligand were downloaded from PubChem. Using PyMOL (Version 2.4.1) software water molecules as well as native ligands from the protein were removed, defined as cleaning/purification of the protein for further application. Using a web server called Deep Site Active Pockets of the proteins were calculated ${ }^{[18]}$. The results calculated by the web server were in the form of different ids, centres and scores. Scoring In deep site was using neural networking based on following instructions using DCNN

architecture.

https://academic.oup.com/bioinformatics/article/33/19 $/ 3036 / 3859178$ Center values for the grid were selected keeping score greater than 0.98 .
UCSF Chimera (Version 1.14) was used to prepare the receptor using Dock Prep function.

Dock Prep prepared structures for Docking using

these functions:

- deleting water molecules

- repairing truncated sidechains

- adding hydrogens

- assigning partial charges

- writing files in Mol2 format

1. In silico Docking Using Auto Dock Vina Auto dock Vina (Version 1.1.2) along with UCSF Chimera (Version 1.14) was used for molecular Docking Studies ${ }^{[1,20]}$. Centre values and size of the grid of different scores were used from DEEPSITE calculations done above.

Following Parameters were set in auto dock vina.

\section{Receptor options -}

- Add hydrogens in Chimera (true/false) - whether to add hydrogens in Chimera before calling the script. The receptor prep script will check for hydrogens and add them if they are missing. Auto Dock Vina needs the polar (potentially H-bonding) hydrogens to identify atom types for scoring purposes.

- Merge charges and remove non-polar hydrogens (true/false) - note Auto Dock Vina does not use charges or nonpolar hydrogens, so this setting is not expected to affect results except for the presence or absence of nonpolar hydrogens in the processed receptor.

- Merge charges and remove lone pairs (true/false) note Auto Dock Vina does not use charges or lone pairs, so this setting is not expected to affect results except for the presence or absence of lone pairs in the processed receptor (and there may not have been any lone pairs to start with)

\section{- Ignore waters (true/false)}

- Ignore chains of non-standard residues (true/false) ignore chains composed entirely of residues other than the 20 standard amino acids.

- Ignore all non-standard residues (true/false) ignore all residues other than the 20 standard amino acids. 


\section{For Ligands}

- Merge charges and remove non-polar hydrogens (true/false) - note Auto Dock Vina does not use charges or nonpolar hydrogens, so this setting is not expected to affect results except for the presence or absence of nonpolar hydrogens in the ligand output files

- Merge charges and remove lone pairs (true/false) note Auto Dock Vina does not use charges or lone pairs, so this setting is not expected to affect results except for the presence or absence of lone pairs in the ligand output files (and there may not have been any lone pairs to start with)

\section{Docking parameters}

- Number of binding modes (1-10, 10) - maximum number of binding modes to generate

- Exhaustiveness of search $(1-8,8)$ - thoroughness of search, roughly proportional to time

- Maximum energy difference ( $\mathrm{kcal} / \mathrm{mol})(1-3,3)-$ maximum score range; binding

modes with scores not within this range of the best score will be discarded. The docking results were calculated by Auto dock vina using it's Scoring function and results were displayed in the form of Scores and RMSD values. Docking results with the highest value score accompanied by negative sign and least RMSD values were chosen for further studies.

\section{Residue Analysis}

PyMOL was used for visualization of interactions of the docked structure at the ligand sites ${ }^{[21]}$.

Discovery Studio $\mathbf{2 0 2 0}$ was used to study the ligand interactions and total number of

residues $^{[22]}$. It was also used to plot the 2D structure of the interactions and residues.

5.Statistical Analysis: Descriptive, estimation and Hypothesis testing with confidence interval of $95 \%$ was applied to data using formula 1 given below ${ }^{[23]}$.

$$
C I=\bar{x} \pm z \frac{s}{\sqrt{n}}
$$

$$
\begin{aligned}
& C I=\text { confidence interval } \\
& \bar{x}=\text { sample mean } \\
& z \quad=\text { confidence level value } \\
& s \quad=\text { sample standard deviation } \\
& n \quad=\text { sample size }
\end{aligned}
$$

\section{RESULTS}

\section{Bioavailability Radar:}

For the further analysis on four selected ligands viz Ciprofloxacin, Diltiazem a more demonstrating and comprehensive study was performed using

\begin{tabular}{|c|c|c|c|c|c|c|c|c|}
\hline Lignnss & $\log P$ & Bionvilibbility score & Lipinhsividue & Molecular weight (I) $\mathrm{mol})$ & 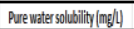 & Plasma Protein Binding & Stinpermedility & Images \\
\hline & & & & & & & & \\
\hline & & & & & & & & \\
\hline \multirow[t]{5}{*}{ Ciprefloxain } & 11 & 0.55 & 0 & 31.24 & 21.4 & 3105 & 4.6 & \\
\hline & & & & & & & & \\
\hline & & & & \multicolumn{2}{|c|}{ Gally yavilbole } & & & \\
\hline & & & & & & & & \\
\hline & & & & & & & & \\
\hline \multirow[t]{4}{*}{ Dititiem } & 281 & 0.55 & 0 & 4452 & 328612 & 70.22 & -3.13 & \\
\hline & & & & & & & & \\
\hline & & & & \multirow{2}{*}{\multicolumn{2}{|c|}{ Oarlyyaildale }} & & & \\
\hline & & & & & & & & \\
\hline
\end{tabular}
bioavailability radar. Bioavailability radar is elucidated tool used for investigation of the drug likeness of the ligands based on eight parameters.

Table 1 : shows the bioavailability radar charts of selected ligands

\section{Molecular Docking:}

The docking result was collected from Auto-Dock vina in the form of Dock score for all the three proteins docked with above mentioned two ligands, average docking Score of each ligand accumulated to average dock score of three proteins were taken. Standard deviation and Confidence interval were reckoned, depending on the confidence interval minimum value of dock score for each ligand was reckoned. All the dock scores above the minimum score could be considered for further evaluations. 
Table.2 : Obtained docking score of protein with respect to the Diltiazem

\begin{tabular}{|c|c|c|c|}
\hline Dock score & LigandS & Protein & Amino acid interactions \\
\hline & & & \\
-7.1 & Diltiazem & $6 \mathrm{BBW}(\mathrm{A})$ & \\
& & & \\
-7.2 & Diltiazem & $6 \mathrm{BBW}(\mathrm{A})$ & \\
& & & \\
\hline
\end{tabular}

Table.2 (Contd,) : Obtained docking score of protein with respect to the Diltiazem

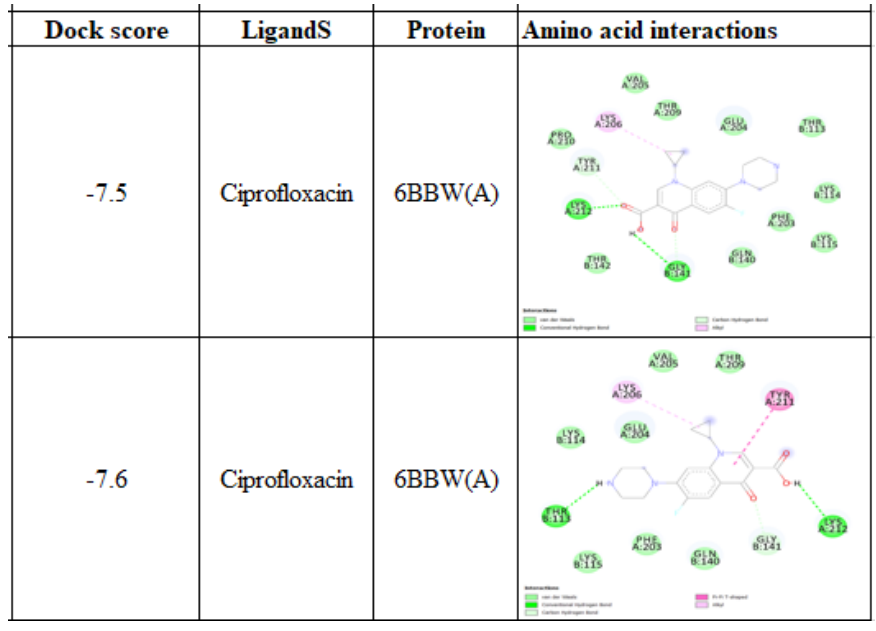

Table.3 : Calculation of the parametres to be measured

\begin{tabular}{|c|c|c|c|c|c|c|c|}
\hline Sl. No. & $\begin{array}{l}\text { Formulation } \\
\text { Code }\end{array}$ & Polymer & $\begin{array}{c}\text { Mean } \\
\text { Particle } \\
\text { Size }(\mathrm{nm}) \pm \\
\text { SD }\end{array}$ & $\begin{array}{c}\text { Size } \\
\text { Distribution }\end{array}$ & $\mathrm{PDI} \pm \mathrm{SD}$ & $\begin{array}{l}\text { Loading } \\
\text { Efficiency* } \\
\quad \pm \text { SD \% }\end{array}$ & $\begin{array}{c}\text { Entrapment } \\
\text { Efficiency }{ }^{*} \pm \\
\text { SD \% }\end{array}$ \\
\hline 1. & NP 1 & Chitosan & $310.04 \pm 32$ & $\begin{array}{c}7.5 \%(48-90 \\
\mathrm{nm}) \\
93.3 \%(200- \\
525 \mathrm{~nm}) \\
\end{array}$ & $0.681 \pm 0.15$ & $18.55 \pm 3$ & $75.5 \pm 4.5$ \\
\hline 2. & NP 2 & Gelatin & $740.07 \pm 45$ & $\begin{array}{c}13.5 \%(70- \\
160 \mathrm{~nm}) \\
86.5 \%(480- \\
1200 \mathrm{~nm}) \\
\end{array}$ & $0.7770 \pm 0.14$ & $9.75 \pm 3$ & $75.3 \pm 5.9$ \\
\hline
\end{tabular}

Table.4: Major peaks observed in the FT-IR spectrum
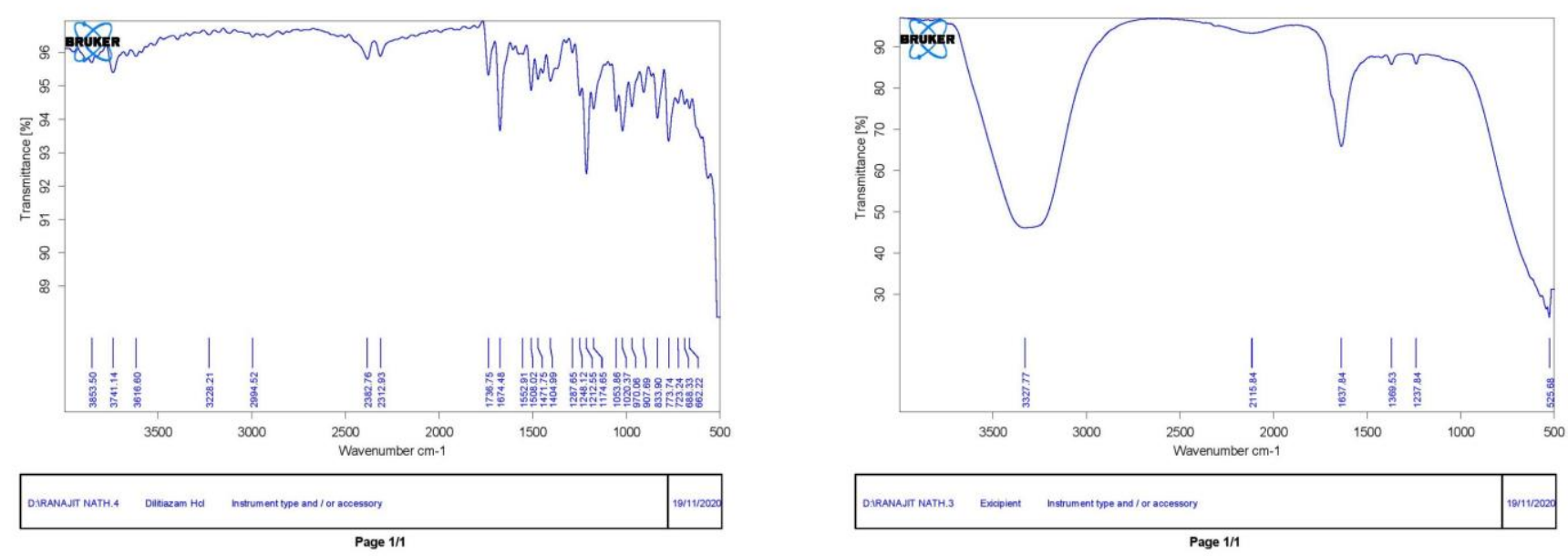


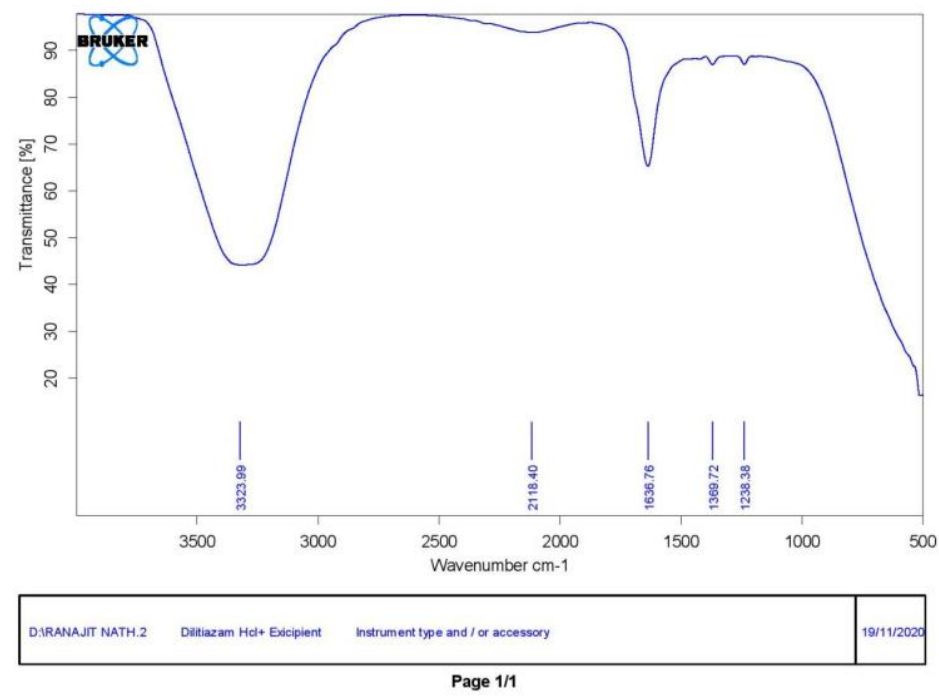

\begin{tabular}{|c|c|c|c|c|c|c|}
\hline $\begin{array}{l}\text { Sl. } \\
\text { No. }\end{array}$ & Bands & \multicolumn{2}{|r|}{ Drug } & \multicolumn{2}{|r|}{ NP 1} & NP 2 \\
\hline 1. & $-\mathrm{OH}$ & \multicolumn{2}{|c|}{3450.8 and $3333.9 \mathrm{~cm}^{-1}$} & \multicolumn{2}{|c|}{$3340.9 \mathrm{~cm}^{-1}$} & 3343.5 and $3234.5 \mathrm{~cm}^{-1}$ \\
\hline 2. & $\mathrm{~N}-\mathrm{H}$ bend, assy. & \multicolumn{2}{|c|}{$1532.5 \mathrm{~cm}^{-1}$} & \multicolumn{2}{|c|}{$1546.4 \mathrm{~cm}^{-1}$} & $1550.8 \mathrm{~cm}^{-1}$ \\
\hline 3. & $\mathrm{C}-\mathrm{C}$ ring str. & \multicolumn{2}{|c|}{1524 and $1475.7 \mathrm{~cm}^{-1}$} & \multicolumn{2}{|c|}{1567.2 and $1432.1 \mathrm{~cm}^{-1}$} & $1465.9 \mathrm{~cm}^{-1}$ \\
\hline 4. & \multicolumn{2}{|c|}{$\begin{array}{c}\text { Aromatic amines, C-N } \\
\text { str. }\end{array}$} & \multicolumn{2}{|c|}{1340.9 and $1340.1 \mathrm{~cm}^{-1}$} & $1377.1 \mathrm{~cm}^{-1}$ & 1240.4 and $1359.5 \mathrm{~cm}^{-1}$ \\
\hline 5. & \multicolumn{2}{|c|}{ Assy. C-O-C str. } & \multicolumn{2}{|c|}{$1546 \mathrm{~cm}^{-1}$} & $1220.8 \mathrm{~cm}^{-1}$ & $1223.2 \mathrm{~cm}^{-1}$ \\
\hline 6. & \multicolumn{2}{|c|}{ Sym C-O-C str. } & \multicolumn{2}{|c|}{$1020 \mathrm{~cm}^{-1}$} & $1009.9 \mathrm{~cm}^{-1}$ & $1090.3 \mathrm{~cm}^{-1}$ \\
\hline 7. & \multicolumn{2}{|c|}{$\mathrm{N}-\mathrm{H}$ wagging } & \multicolumn{2}{|c|}{900.7 and $856.2 \mathrm{~cm}^{-1}$} & $900.5 \mathrm{~cm}^{-1}$ & $897.5 \mathrm{~cm}^{-1}$ \\
\hline 8. & \multicolumn{2}{|c|}{$\begin{array}{l}\text { Mono-substitution in } \\
\text { ring }\end{array}$} & \multicolumn{2}{|c|}{$\begin{array}{c}\text { 787.1,756.7 and } 684.2 \\
\mathrm{~cm}^{-1}\end{array}$} & $\begin{array}{l}776.6 \text { and } \\
665 \mathrm{~cm}^{-1}\end{array}$ & 772.5 and $676.5 \mathrm{~cm}^{-1}$ \\
\hline
\end{tabular}

\section{v. CONCLUSION}

Depending on the docking with respect to $6 \mathrm{BBW}$ protein, diltiazem \& ciprofloxacin were high potent towards inhibit group A Streptococcus (GAS or Streptococcus pyogenes) targeted protein 6BBW which is reason behind RHD. Also, with the help of the MIE theory it can be suggested that this formulation can go for further evaluation.

\section{REFERENCES}

[1]. Watkins DA, Beaton AZ, Carapetis JR, Karthikeyan G, Mayosi BM, Wyber R, m.fl. Rheumatic Heart Disease Worldwide: JACC 
Scientific Expert Panel. J Am Coll Cardiol 2018;72(12):1397-416.

[2]. Cunningham MW. Post-Streptococcal Autoimmune Sequelae: Rheumatic Fever and Beyond. Streptococcus pyogenes Basic Biol to Clin Manifestations [Internet] 2016;1-37. Available from: http://www.ncbi.nlm.nih.gov/pubmed/2686623 5

[3]. Tandon R, Sharma M, Chandrashekhar Y, Kotb M, Yacoub MH, Narula J. Revisiting the pathogenesis of rheumatic fever and carditis. Nat. Rev. Cardiol.2013;10(3):171-7.

[4]. Pala R, Anju VT, Dyavaiah M, Busi S, Nauli SM. Nanoparticle-Mediated Drug Delivery for the Treatment of Cardiovascular Diseases. Int J Nanomedicine 2020;15:3741-69.

[5]. Bowman DM. More than a Decade On: Mapping Today's Regulatory and Policy Landscapes Following the Publication of Nanoscience and Nanotechnologies: Opportunities and Uncertainties. Nanoethics 2017;11(2):169-86.

[6]. De Jong WH, Borm PJA. Drug delivery and nanoparticles: Applications and hazards. Int J Nanomedicine 2008;3(2):133-49.

[7]. Gupta AK, Gupta M. Synthesis and surface engineering of iron oxide nanoparticles for biomedical applications. Biomaterials 2005;26(18):3995-4021.

[8]. Veiseh O, Tang BC, Whitehead KA, Anderson DG, Langer R. Managing diabetes with nanomedicine: Challenges and opportunities. Nat Rev Drug Discov 2014;14(1):45-57.

[9]. Goldstein EJ. Norfloxacin, a fluoroquinolone antibacterial agent. Classification, mechanism of action, and in vitro activity. Am J Med 1987;82(6B):3-17.

[10]. Young PG, Raynes JM, Loh JM, Proft T, Baker EN, Moreland NJ. Group A Streptococcus $t$ antigens have a highly conserved structure concealed under a heterogeneous surface that has implications for vaccine design. Infect Immun 2019;87(6):1-13.

[11]. Wolfram H, Wriedt T. The Mie Theory Basics and Applications. 2012.

[12]. Lv PP, Wei W, Yue H, Yang TY, Wang LY, Ma GH. Porous quaternized chitosan nanoparticles containing paclitaxel nanocrystals improved therapeutic efficacy in non-small-cell lung cancer after oral administration. Biomacromolecules 2011;12(12):4230-9.

[13]. Aman RM, Zaghloul RA, El-Dahhan MS. Formulation, optimization and characterization of allantoin-loaded chitosan nanoparticles to alleviate ethanol-induced gastric ulcer: in-vitro and in-vivo studies. Sci Rep 2021;11(1).

[14]. Mali B, Moharil SN, Mhasal V, Narkhede MB. Drug-Excipient Interaction Study of Tramadol $\mathrm{HCl}$ with polymers. World J Pharm Res 2017;6(13):848-61.

[15]. Daina A, Michielin O, Zoete V. SwissADME: a free web tool to evaluate pharmacokinetics, drug-likeness and medicinal chemistry friendliness of small molecules. Sci Rep 2017;7:42717.

[16]. Berman HM, Kleywegt GJ, Nakamura H, Markley JL. The Protein Data Bank archive as an open data resource. J Comput Aided Mol Des [Internet] 2014;28(10):1009-14. Available from: https://doi.org/10.1007/s10822-014-9770-y

[17]. Berman HM, Westbrook J, Feng Z, Gilliland G, Bhat TN, Weissig H, m.fl. The Protein Data Bank. Nucleic Acids Res [Internet] 2000;28(1):235-42. Available from: https://doi.org/10.1093/nar/28.1.235

[18]. Jiménez J, Doerr S, Martínez-Rosell G, Rose AS, De Fabritiis G. DeepSite: protein-binding site predictor using 3D-convolutional neural networks. Bioinformatics 2017;33(19):3036-42.

[19]. Pettersen EF, Goddard TD, Huang CC, Couch GS, Greenblatt DM, Meng EC, m.fl. UCSF Chimera - A visualization system for 
exploratory research and analysis. J Comput Chem 2004;25(13):1605-12.

[20]. Trott O, Olson AJ. AutoDock Vina: Improving the speed and accuracy of docking with a new scoring function, efficient optimization, and multithreading. J Comput Chem 2009;31(2):NANA.

[21]. L DeLano W. Pymol: An open-source molecular graphics tool. \{CCP4\} Newsl Protein Crystallogr [Internet] 2002;40:1-8. Available from: http://www.ccp4.ac.uk/newsletters/newsletter4 0/11_pymol.pdf

[22]. Kemmish H, Fasnacht M, Yan L. Fully automated antibody structure prediction using BIOVIA tools: Validation study. PLoS One 2017;12(5):1-26.

[23]. Love J, Selker R, Marsman M, Jamil T, Dropmann D, Verhagen J, m.fl. JASP: Graphical statistical software for common statistical designs. J Stat Softw 2019;88(1).

\section{Cite this article as :}

Ranajit Nath, Ratna Roy, Ritam Bandopadhyay, Soubhik Bhattacharyya, Riya Biswas, " A Unique Approach to Treat Rheumatic Heart Disease by Using In Silico Modeling With Polymeric Nanoparticles", International Journal of Scientific Research in Science and Technology(IJSRST), Print ISSN : 2395-6011, Online ISSN : 2395-602X, Volume 8, Issue 3, pp.885893, May-June-2021. Available at doi : https://doi.org/10.32628/IJSRST2183190 Journal URL : https://ijsrst.com/IJSRST2183190 